\title{
Estimation of direct and indirect cost of diabetes in Morocco
}

\author{
Wiam Boutayeb $^{1}$, Mohamed E. N. Lamlili ${ }^{1}$, Abdesslam Boutayeb ${ }^{2}$, Saber Boutayeb ${ }^{3}$ \\ ${ }^{1}$ Department of Mathematics, Faculty of Sciences, University Mohamed 1st, Oujda, Morocco \\ ${ }^{2}$ Laboratory of Stochastic and Determinist Modeling, Research Unit Associated to CNRST, Faculty of Sciences, University Mo- \\ hamed 1st, Oujda, Morocco \\ ${ }^{3}$ Department of Medical Oncology, National Institute of Oncology, Rabat, Morocco \\ Email:wiam.boutayeb@gmail.com, Mohamed.lamlili@gmail.com,x.boutayeb@menara.ma, boutayebdr@yahoo.fr
}

Received 8 March 2013; revised 10 April 2013; accepted 18 April 2013

Copyright (C) 2013 Wiam Boutayeb et al. This is an open access article distributed under the Creative Commons Attribution License, which permits unrestricted use, distribution, and reproduction in any medium, provided the original work is properly cited.

\begin{abstract}
Due to its chronic nature with severe complications, diabetes needs costly prolonged treatment and care. The high economic burden of diabetes is particularly threatening low and middle income countries. Worldwide, studies have shown that the cost of diabetes per person is much higher than the per capita health expenditure. This study is the first to estimate the direct and indirect cost of diabetes in Morocco. The direct cost of diabetes was computed by assuming three scenarios of prices (low, medium and high) due to different prices of insulin, oral drugs and other items used in diabetes treatment and care. Indirect costs of diabetes were estimated by the lifetime forgone earnings caused by premature death and disability due to diabetes. The direct cost of diabetes in Morocco was estimated to be between US $\$ 0.47$ and US $\$ 1.5$ billion whereas the indirect cost was estimated to be around US $\$ 2$ billion accounting for $57 \%$ of the total cost of diabetes under the high cost scenario, $69 \%$ under the medium scenario and $81 \%$ under the low cost scenario. The average per capita indirect cost was estimated to be US $\$ 1113$, relatively higher than the direct cost of diabetes which was seen to vary from US\$ 259 to US $\$ 830$. The results yielded by this study were compared to those obtained by similar studies in different regions and countries of the world. As a conclusion, the findings of this study indicate a high economic burden of diabetes and stress the importance that Moroccan health decision makers should give to sensitisation, early diagnosis and treatment of diabetes especially with the crucial growing trend of diabetes prevalence.
\end{abstract}

Keywords: Diabetes; Direct Cost; Indirect Cost; Prevalence; Productive Life Years; Disability

\section{INTRODUCTION}

Once associated with economic development and considered as diseases of the rich, noncommunicable diseases (NCDs) are now affecting countries worldwide, threatening particularly economic and human development of low and middle-income countries. Diabetes is one of these diseases having a high prevalence and consequently a substantial socio-economic burden. Due to its chronic nature with severe complications, diabetes needs costly prolonged treatment and care. Consequently, its economical burden affects individuals, households and the whole society and raises the equity problem between and within countries [1]. In India, a low-income family with an adult diabetic spends about $25 \%$ of its family income on diabetes care [2]. In the Eastern District of Abu Dhabi emirate (Al-Ain region), Al-Maskari estimated that the annual direct treatment cost of a diabetic patient without complications (US \$1605) was 3.2 times higher than the per capita expenditure for health care in the UAE (US \$497). The cost increased notably with the presence of micro-vascular complications (2.2 times) and macro-vascular complications (6.4 times) [3].

In 2003, Barcelo et al. carried out a study on the cost of diabetes in Latin America and the Caribbean Region (LACR). The direct cost of diabetes in the 26 countries of LACR was estimated at US $\$ 10.72$ billion with medication (insulin and oral drugs) accounting for $44 \%$, hospitalization (9.4\%), consultations (23.4\%) and treatment of complications (23.2\%). The indirect cost of diabetes (US $\$ 54.5$ billion) accounted for US $\$ 83.5 \%$ of the total cost [4].

In the WHO African region, Kirigia et al. found that the average cost per person with diabetes in income groups 1, 2 and 3 was around Int\$11430, Int\$ 4770 and Int\$ 2144 respectively. The total economic loss for the 
whole region was Int\$2 25.51 billion (PPP). Direct cost accounted for $32 \%$, with one third devoted to cost of insulin while the remaining $68 \%$ for indirect cost of diabetes was dominantly caused by permanent disability (88.5\%) [5].

Recent Korean studies estimate the cost of Type2 diabetes without complications is approximately US $\$ 1184$ per patient per year. In contrast, diabetes with microvascular complications costs up to 4.7 times that amount, and diabetes with macrovascular complications incur up to 10.7 times [6].

The American Diabetes Association estimates that the yearly cost for treating a person with diabetes is over 5 times more than for a person without diabetes [7]. According to the Canadian Diabetes Association, the economic burden of diabetes nearly doubled between the years 2000 (CA \$6.3 billion) and 2010 (CA \$12.2). The direct cost of diabetes now accounts for about 3.5\% of public healthcare spending in Canada [8].

The report published by Diabetes UK in 2010 indicated that up to $10 \%$ of hospital budgets were spent on treating diabetes and its complications, and beside the cost covered by NHS, people with diabetes were spending over $£ 500$ million of their own money on coping with the condition in 2004. Diabetes is the leading cause of blindness in people of working age in UK, the rate of lower limb amputation in people with diabetes is 15 times higher than in people without diabetes and $80 \%$ of people with diabetes will die from CVDs [9].

\section{METHODS}

As in many developing countries, accurate estimation of diabetes prevalence is lacking in Morocco, and reliable data on diabetes constitute a real problem either for the prevalence and number of people with diabetes or for the cost related to treatment of diabetes and its complications (cost of drugs, hospitalizations, biological tests, visits to physicians etc $\cdots$ ).

\section{PREVALENCE OF DIABETES}

For the number of people with Type 2 diabetes, our study was based on values provided by the International Diabetes Federation (IDF) [10], World Health Organization (WHO) [11], Moroccan ministry of Health [12] and studies published in reviewed journals [13-15]. All computations of costs were based on the assumption that prevalence of Type 2 diabetes among adult people was $9 \%$ and that prevalence of Type 1 diabetes was 70/100,000 among the whole population.

\section{DIRECT COST OF DIABETES}

Large variability of prices between NGOs, public and private health sectors was found for the cost related to treatment of diabetes (insulin, oral drugs, syringes, reagent strips, glucose meters, lancets, biological tests and hospitalization). Prices of different types of insulin and anti-diabetic oral drugs can be found in the Website of the National Agency of Health Insurance [16]. To overcome the problem of disparity in prices, three scenarios were used (Low, Medium and High price).

\subsection{Insulin and Syringes}

The annual cost of insulin and syringes per person was calculated by assuming that all Type 1 diabetics $(N 1)$ and $25 \%$ of Type 2 diabetics $(0.25 \times N 2)$ use insulin and syringes. Assuming that $13,000 \mathrm{UI}$ is the annual average number of insulin units needed per patient (corresponding to around 35 UI per day) and 200 syringes are needed by each patient per year, the annual cost of insulin and syringes per patient was calculated for three price values per UI and syringe (pl: low price, pm: medium price and ph: high price).

Annual average low cost per patient

$$
=(N 1+0.25 \times N 2) \times(13000 \times \operatorname{pl}(\mathrm{i})+200 \times \mathrm{pl}(\mathrm{s}))
$$

Annual average medium cost per patient

$$
=(N 1+0.25 \times N 2) \times(13000 \times \mathrm{pm}(\mathrm{i})+200 \times \mathrm{pm}(\mathrm{s}))
$$

Annual average high cost per patient

$$
=(N 1+0.25 \times N 2) \times(13000 \times \mathrm{ph}(\mathrm{i})+200 \times \mathrm{ph}(\mathrm{s}))
$$

\subsection{Oral Drugs}

To estimate the annual cost of oral drugs, it was assumed that $3 \%$ of Type $1(0.03 \times N 1)$ and $65 \%$ of Type 2 diabetics $(0.65 \times N 2)$ use oral drugs at a level of 1000 tablets per year per patient. Again the total cost of oral drugs was calculated for three values per tablet (low, medium, high). Metformin (Daonil) and Glibenclamide (Glucophage) were the oral drugs the most used.

Annual low cost per patient

$=(0.03 \times N 1+0.65 \times N 2) \times 1000 \times \mathrm{pl}$

Annual medium cost per patient

$=(0.03 \times N 1+0.65 \times N 2) \times 1000 \times \mathrm{pm}$

Annual high cost per patient

$=(0.03 \times N 1+0.65 \times N 2) \times 1000 \times \mathrm{ph}$

\subsection{Reagent Strips, Urine Strips, Lancets, Glucose Meters}

Following the previous procedure for insulin and oral drugs, the annual cost of lancets (la), reagent strips (rs), urine strips (us) and glucose meters (gm) was calculated according to low-medium-high scenarios of prices. The 
number of people with diabetes using these four items was assumed to be equal to all Type1 diabetics plus 33\% of Type 2 diabetics $(N 1+0.33 \times N 2)$. Assuming that each patient uses 100 lancets, 300 reagent strips and 100 urine strips per year and a glucose meter with an eight year useful life, the annual cost of lancets + reagent strips + glucose meter per patient per year can be expressed, according to the low-medium-high scenarios, by the following formulae:

Annual average low cost

$$
=(N 1+0.33 \times N 2) \times(\operatorname{pl}(\mathrm{la})+\mathrm{pl}(\mathrm{rs})+\mathrm{pl}(\mathrm{us})+\mathrm{pl}(\mathrm{gm}) / 8)
$$

Annual average medium cost

$=(N 1+0.33 \times N 2) \times(\mathrm{pm}(\mathrm{la})+\mathrm{pm}(\mathrm{rs})+\mathrm{pm}(\mathrm{us})+\mathrm{pm}(\mathrm{gm}) / 8)$

Annual average high cost

$$
=(N 1+0.33 \times N 2) \times(\mathrm{ph}(\mathrm{la})+\mathrm{ph}(\mathrm{rs})+\mathrm{ph}(\mathrm{us})+\mathrm{ph}(\mathrm{gm}) / 8)
$$

\subsection{Laboratory Tests}

People with diabetes usually need some regular tests in order to control their disease and to avoid delayed diagnosis of complications that may affect eyes, kidneys, feet, and others. It is assumed that, in average, 75\% of Type 1 and $25 \%$ of Type 2 diabetics will require one $\mathrm{HbA}_{1 \mathrm{C}}$ test $(\mathrm{t} 1)$, one lipid profile $(t 2)$, one proteinuria $(t 3)$, one electrocardiogram ( $t 4)$, one eye examination $(t 5)$ per year. The annual cost is obtained according to the three scenarios of low-medium-high prices.

$$
\begin{aligned}
& \text { Annual average low cost }=(0.75 \times N 1+0.25 \times N 2) \\
& \times[\operatorname{pl}(t 1)+\operatorname{pl}(t 2)+\operatorname{pl}(t 3)+\operatorname{pl}(t 4)+\operatorname{pl}(t 5)]
\end{aligned}
$$

Annual average medium cost $=(0.75 \times N 1+0.25 \times N 2)$

$\times[\mathrm{pm}(t 1)+\mathrm{pm}(t 2)+\mathrm{pm}(t 3)+\mathrm{pm}(t 4)+\mathrm{pm}(t 5)]$

Annual average high cost $=(0.75 \times N 1+0.25 \times N 2)$

$$
\times[\mathrm{ph}(t 1)+\mathrm{ph}(t 2)+\mathrm{ph}(t 3)+\mathrm{ph}(t 4)+\mathrm{ph}(t 5)]
$$

\subsection{Outpatient Consultation}

Estimation of the outpatient consultation cost was calculated according to the low-medium-high scenarios by assuming that each patient with diabetes needs 4 visits per year. The low, medium and high prices are related to the kind of health service (public, private, NGO) and the type of visit (to general practitioner or specialist).

$$
\text { Annual average low cost }=4 \times(N 1+N 2) \times \mathrm{pl}
$$

Annual average medium cost $=4 \times(N 1+N 2) \times \mathrm{pm}$

$$
\text { Annual average high cost }=4 \times(N 1+N 2) \times \mathrm{ph}
$$

\subsection{Inpatient Consultation and Hospitalization}

In addition to the 4 outpatient visits per year assumed for all people with diabetes, it is assumed that, in average, $75 \%$ of Type 1 and $25 \%$ of Type 2 diabetics will require a 7days hospitalisation per year. Again, the price of hospitalisation was evaluated according to a low-mediumhigh price, depending of the kind of hospitalisation service.

$$
\begin{aligned}
& \text { Annual average low cost } \\
& =7 \times(0.75 \times N 1+0.25 \times N 2) \times \mathrm{pl}
\end{aligned}
$$

Annual average medium cost

$$
=7 \times(0.75 \times N 1+0.25 \times N 2) \times \mathrm{pm}
$$

Annual average high cost

$$
=7 \times(0.75 \times N 1+0.25 \times N 2) \times \mathrm{ph}
$$

\section{INDIRECT COST OF DIABETES}

Indirect economic cost of a disease is mainly estimated by the cost of premature mortality, permanent and temporarily disability caused by this illness. It should be stressed, however, that these non-medical costs are difficult to measure. Beside the problem raised by what to include in indirect costs and how to measure and value such economic costs, overlapping and double counting that may result from indirect cost estimation constitute a subject of discussion and debate among researchers [17]. Usually, three approaches are used to estimate indirect costs of diseases: human capital, willingness-to-pay and friction costs. In this study, following Barcelo et al. [4], we use the first approach in which indirect costs of diabetes are estimated by the lifetime forgone earnings caused by premature death and disability due to diabetes.

\subsection{Mortality Cost}

Following the method used by Kirigia et al. [5] and using the probabilities of diabetes associated deaths in different age groups given by Murray and Lopez [18], the number of productive years lost by people aged 15 to 60 years was estimated by subtracting the averages of age of onset and duration of diabetes from life expectancy of the country. For children and adolescents, productive years lost was calculated by subtracting the averages of age of onset and duration of diabetes plus 14 years from life expectancy of the country.

\subsection{Cost of Permanent Disability Caused by Diabetes}

Following Barcelo et al. [4], we assumed that $5 \%$ of the total population with diabetes was permanently disabled. 
The estimated cost of permanent disability was calculated by multiplying the number of productive years lost to disability by the per capita GDP.

\subsection{Cost of Temporarily Disability Caused by Diabetes}

The cost of diabetes-related disability was estimated for people with diabetes aged 15 to 60 years. The cost of disability in young people $(0-14)$ and those retired (above 60 years) was ignored. It should be stressed that, following Barcelo et al. [4] and Kirigia et al. [5], we assumed that $40 \%$ of the population with diabetes aged $<60$ years were economically active and that 60 years is the age of retirement for the quasi-totality of Moroccan citizens in 2011.

A computer program was written, using Excel to compute all the economic costs.

\section{INTANGIBLE COSTS}

Diabetes is a chronic disease with a high economic burden affecting rich and poor people worldwide. However, its burden goes beyond the limits of economical problems. The disease incurs also costs that are intangible and not quantifiable such as inconvenience, anxiety, pain, and more generally lower quality of life [2]. Indeed, diabetes causes more than half of all non-traumatic lower limb amputations. It is also one of the leading causes of visual impairment and blindness, and the leading cause of renal failure in many developing countries. How can we evaluate financially the loss of vision, kidneys or lower limb? And how can we estimate the affective care devoted by a family to one of its members affected by diabetes complications? As indicated earlier, the treatment of diabetes appears not only as an economic problem but also as a sustainable development issue. For this reason, health decision makers should consider such a disease in its integrated context, requiring health education and sensitization, early diagnosis and efficient treatment to avoid complications or at least to delay them as far as possible. For instance, the budget required for sensitization, diagnosis and treatment of diabetes without complications is cost-efficient compared to the socioeconomic burden imposed by blindness, kidney failure or foot amputation.

\section{RESULTS}

As indicated in Table 1, the direct cost of diabetes in Morocco is estimated to be US $\$ 0.47$ billion, US $\$ 0.9$ billion and US $\$ 1.5$ billion respectively following the low, medium and high scenarios of cost. Insulin and oral drugs account for $18 \%$ to $35 \%$. The average per capita direct cost of diabetes is estimated at US \$259 (low cost), US $\$ 495$ (medium cost) and US $\$ 830$ (high cost).
Table 1. Direct cost of diabetes in Morocco.

\begin{tabular}{|c|c|c|c|}
\hline \multicolumn{4}{|c|}{ Direct cost of diabetes in Morocco } \\
\hline Total population $\mathrm{Nt} \times 1000$ & & 31,950 & \\
\hline Adult population $\mathrm{Na} \times 1000$ & & 19,965 & \\
\hline $\begin{array}{l}\text { Prevalence of Type } 1 \\
\text { diabetes (per } 100,000 \text { ) }\end{array}$ & & 70 & \\
\hline $\begin{array}{l}\text { Prevalence of Type } 2 \\
\text { diabetes (\%) }\end{array}$ & & 9 & \\
\hline $\begin{array}{l}\text { Number of people with } \\
\text { Type } 1 \text { diabetes }\end{array}$ & & 22,365 & \\
\hline $\begin{array}{l}\text { Number of people with } \\
\text { Type } 2 \text { diabetes }\end{array}$ & & $1,796,850$ & \\
\hline $\begin{array}{l}\text { Total number of people } \\
\text { with diabetes mellitus }\end{array}$ & & $1,819,215$ & \\
\hline $\begin{array}{l}\text { Direct cost of diabetes } \\
\text { according to } \\
\text { different scenarios cost }\end{array}$ & Low & Medium & High \\
\hline $\begin{array}{l}\text { Number of diabetics using } \\
\text { Insulin }(N 1+0.25 N 2)\end{array}$ & & 471,577 & \\
\hline Price of insulin (US \$) & 33 & 325 & 390 \\
\hline Price of 200 syringes (US \$) & 5 & 20 & 40 \\
\hline $\begin{array}{l}\text { Total cost of insulin } \\
\text { and syringes/year }\end{array}$ & $17,919,945$ & $162,694,238$ & 202,778,325 \\
\hline Price of oral drugs & 0.08 & 0.13 & 0.19 \\
\hline Total cost of oral drugs/year & $90,685,180$ & $154,024,571$ & $217,363,962$ \\
\hline $\begin{array}{l}\text { Diabetics who require } \\
\text { Hospitalization } \\
(0.75 \times N 1+0.25 \times N 2)\end{array}$ & & 465,986 & \\
\hline Cost of hospitalisation & 25 & 50 & 100 \\
\hline Total cost of hospitalization & $81,547,594$ & $163,095,188$ & $326,190,375$ \\
\hline Price of 100 lancets (US \$) & 10 & 20 & 30 \\
\hline $\begin{array}{l}\text { Price of one glucose } \\
\text { meter (US \$) }\end{array}$ & 25 & 100 & 300 \\
\hline Price of 100 urine strips (US \$) & 4 & 10 & 18 \\
\hline $\begin{array}{l}\text { Price of } 300 \text { reagent } \\
\text { strips (US \$) }\end{array}$ & 90 & 120 & 300 \\
\hline $\begin{array}{l}\text { Number of diabetics using } \\
\text { lancets, glucose meters, } \\
\text { reagent strips and urine } \\
\text { strips: }(N 1+0.33 N 2)\end{array}$ & & 621,255 & \\
\hline $\begin{array}{l}\text { Cost of lancets, glucose } \\
\text { meters, reagent strips } \\
\text { and urine strips }\end{array}$ & $66,551,953$ & $100,953,955$ & $239,493,843$ \\
\hline $\begin{array}{l}\text { Test (HbA1c, lipids, eye, blood } \\
\text { test, electrocardiogram) }\end{array}$ & 70 & 100 & 150 \\
\hline $\begin{array}{l}\text { Diabetics who require tests } \\
(0.75 \times N 1+0.25 \times N 2)\end{array}$ & & 465,986 & \\
\hline Total cost of tests & $32,619,037$ & $46,598,625$ & $69,897,937$ \\
\hline Outpatient consultation & 25 & 37 & 62 \\
\hline $\begin{array}{c}\text { Outpatient consultation } \\
\text { per year }(* 4)\end{array}$ & $181,921,500$ & $272,882,250$ & $454,803,750$ \\
\hline $\begin{array}{l}\text { Total direct cost of diabetes } \\
\text { in Morocco per year (US \$) }\end{array}$ & $471,245,209$ & $900,48,825$ & $1,510,528,192$ \\
\hline $\begin{array}{l}\text { Direct cost per patient } \\
\text { per year (US \$) }\end{array}$ & 259 & 495 & 830 \\
\hline
\end{tabular}


The indirect cost was estimated to be around US \$2 billion accounting for $57 \%$ of the total cost of diabetes under the high cost scenario, 69\% under the medium scenario and $81 \%$ under the low cost scenario (Table 2). The average per capita indirect cost was estimated to be US $\$ 1113$.

\section{DISCUSSION}

The per capita direct cost of diabetes in Morocco is between US \$259 and US \$830 per year, representing 1.75 to 5.6 times the per capita health expenditure (US \$148). This result may be compared to different estimations published worldwide.

According to IDF estimates in 2011, an average of US $\$ 1274$ per person with diabetes was spent globally on treating and managing the disease. In Arab countries, the average spending per person was estimated at US \$428 per person with diabetes and the estimation for Morocco was US \$235 [10].

In Latin America and the Caribbean Region (LACR), Barcelo et al estimated that the average per capita direct cost of diabetes (US \$703) was 3.2 times higher than the per capita health expenditure (US \$220) in the 26 countries of the LACR [4].

In the Eastern District of Abu Dhabi emirate (Al-Ain region), Al-Maskari estimated that the annual direct treatment costs of a diabetic patient without complications (US \$1605) was 3.2 times higher than the per capita expenditure for health care in the UAE (US \$497). The cost increased notably with the presence of microvascular complications (2.2 times) and macro-vascular complications (6.4 times) [3].

In USA, the yearly cost for treating a person with diabetes is over 5 times more than for a person without diabetes (US \$13243 vs US \$2560) [7].

Korean studies estimate that cost of Type 2 diabetes without complications is approximately US $\$ 1184$ per patient per year. In contrast, diabetes with microvascular complications costs up to 4.7 times that amount, and diabetes with macrovascular complications incur up to 10.7 times [6].

In Pakistan, the annual mean direct cost for each person with diabetes was estimated at US \$197 [19].

The total economic cost of diabetes in Morocco was estimated to be between US \$2.5 billion and US \$3.5 billion with indirect cost accounting for $57 \%$ to $81 \%$. Our study shows a dominance of indirect cost comparable to that obtained by Kirigia et al. in the WHO African region (indirect cost 68\%) [4]. Similarly, for the 26 countries of Latin America and the Caribbean Region, the loss of productivity due to permanent and non permanent disability, and mortality related to diabetes was responsible for an indirect cost of US $\$ 54.5$ billion, representing $83.5 \%$ of the total cost of diabetes in LACR.
Table 2. Indirect cost of diabetes in Morocco.

\begin{tabular}{|c|c|}
\hline \multicolumn{2}{|l|}{ Indirect cost of diabetes in Morocco } \\
\hline Permanent Disability & \\
\hline $\begin{array}{c}\text { Number of people permanently disabled by } \\
\text { diabetes }(4.5 \%)\end{array}$ & 81,865 \\
\hline Number of permanently disabled aged 0 - 4 years & 41 \\
\hline Number of permanently disabled aged 5 - 14 years & 41 \\
\hline Number of permanently disabled aged 15 - 44 years & 8186 \\
\hline Number of permanently disabled aged 45 - 59 years & 25,296 \\
\hline Number of permanently disabled aged $60+$ years & 48,300 \\
\hline $\begin{array}{l}\text { Discounted years of permanent disability: } \\
0-4 \text { years per person }\end{array}$ & 0.6 \\
\hline $\begin{array}{l}\text { Discounted years of permanent disability: } \\
\qquad 5-14 \text { years per person }\end{array}$ & 2.8 \\
\hline $\begin{array}{l}\text { Discounted years of permanent disability: } \\
15-44 \text { years per person }\end{array}$ & 19.6 \\
\hline $\begin{array}{l}\text { Discounted years of permanent disability: } \\
45-59 \text { years per person }\end{array}$ & 12.6 \\
\hline $\begin{array}{l}\text { Discounted years of permanent disability: } \\
\qquad 60+\text { years per person }\end{array}$ & 0.0 \\
\hline Average GDP income per capita (US \$) & 3109 \\
\hline Total cost of permanent disability (US \$) & $1,486,940,942$ \\
\hline \multicolumn{2}{|l|}{ Temporary Disability } \\
\hline $\begin{array}{l}\text { Number of people temporary disabled by diabetes } \\
\qquad(40 \%)\end{array}$ & 582,149 \\
\hline Number of $60+$ temporarily disabled patients (50\%) & 343,468 \\
\hline Days of temporary disablement per person per year (4) & 4 \\
\hline Daily GDP per capita (US \$) & 8.5 \\
\hline Total cost of temporary disability (US \$) & $19,832,628$ \\
\hline \multicolumn{2}{|l|}{ Mortality caused by diabetes } \\
\hline Number of deaths in 0 - 4 years ( $8 \%)$ & 2343 \\
\hline Number of deaths in 5 - 14 years (8\%) & 2343 \\
\hline Number of deaths in 15 - 44 years (8\%) & 2343 \\
\hline Number of deaths in 45 - 59 years (16\%) & 4686 \\
\hline Number of deaths in $60+$ years $(60 \%)$ & 17,574 \\
\hline $\begin{array}{l}\text { Discounted future potential life years lost } \\
\text { in } 0-4 \text { per person }\end{array}$ & 27 \\
\hline $\begin{array}{l}\text { Discounted future potential life years lost } \\
\text { in } 5-14 \text { per person }\end{array}$ & 24.5 \\
\hline $\begin{array}{l}\text { Discounted future potential life years lost } \\
\text { in } 15-44 \text { per person }\end{array}$ & 11 \\
\hline $\begin{array}{l}\text { Discounted future potential life years lost } \\
\text { in } 45 \text { - } 59 \text { per person }\end{array}$ & 5 \\
\hline Total cost of potential life years lost (US \$) & $517,757,550$ \\
\hline Total indirect cost of diabetes(US \$) & $2,024,531,120$ \\
\hline Indirect cost per patient per year (US \$) & 1113 \\
\hline
\end{tabular}

In contrast, for the United States of America, it was estimated that US \$174 billion was spent on diabetes in 2007. The direct cost (US $\$ 116$ billion) accounted for 2/3 
of the total cost incurred by diabetes [7].

In absence of registries and reliable data, it is difficult to know accurately the number of people using insulin, oral drugs, biological tests, glucose meters and hospitalization. For instance, we think that some assumptions made by Kirigia et al. [5] are very conservative and should lead to an underestimated direct cost of diabetes. We have addressed a critical reader's comment to the Journal which published the paper, indicating among others [20], that 1) Kirigia et al. assumed that only people using insulin (Type $1+5 \%$ of Type 2) were using reagent strips and glucose meters. This assumption is controversial because the vast majority of the literature on diabetes [10,17,21-23] recommends that people with Type 2 diabetes on insulin and/or tablets should regularly control their blood glucose, while the authors have considered only one HbA test per year. 2) Similarly, the authors assumed that only people using insulin (Type $1+$ $5 \%$ of Type 2) were facing hospitalization. This may be true in the case of hypoglycemic coma but in general, diabetes patients not using insulin are also susceptible to need hospitalizations especially with age and bad control.

\section{Study Limitations}

In our study, we were limited by lack and scarcity of reliable data. Other limitations were related to different assumptions concerning the number of people using insulin, oral drugs, glucose meters and those needing outpatient care or inpatient hospitalization.

\section{CONCLUSION}

In this paper, we provided an estimation of the economic cost of diabetes in Morocco, incurred directly by the use of insulin, oral drugs and other items needed for diabetes treatment and care; and the loss of productivity caused by disability and premature mortality due to diabetes. Our results were compared to similar estimations provided by published studies carried out in different countries and regions of the world. We also indicated the intangible and not quantifiable costs such as inconvenience, anxiety, pain, and more generally lower quality of life. The findings of this study indicate the high socio-economic burden of diabetes and stress the importance that Moroccan health decision makers should give to sensitisation, early diagnosis and treatment of diabetes especially with the crucial growing trend of diabetes prevalence.

\section{ACKNOWLEDGEMENTS}

This research was partially supported by CNRST (URAC04).

\section{REFERENCES}

[1] Boutayeb, A. and Boutayeb, S. (2005) The burden of
NCDs in developing countries. International Journal for Equity in Health, 4, 2. doi:10.1186/1475-9276-4-2

[2] World Health Organisation (2010) The cost of diabetes. http://www.who.int/mediacentre/factsheets/fs236/en/

[3] Al-Maskari, F., El-Sadig, M. and Nagelkerke, N. (2010) Assessment of the direct medical costs of diabetes mellitus and its complications in the United Arab Emirates. BMC Public Health, 10, 679.

http://www.biomedcentral.com/174-2458/10/679 doi:10.1186/1471-2458-10-679

[4] Barcelo, A., Aedo, C., Rajpathak, S. and Robles, S. (2003) The cost of diabetes in Latin America and the Caribbean. Bulletin of the World Health Organization, 81, 19-27.

[5] Kirigia, J.M., Sambo, H.B., Sambo, G. and Barry, S.P. (2009) Economic burden of diabetes in the WHO African region. BMC International Health and Human Rights, 9, 6. http://www.biomedcentral.com/1472-698X/9/8 doi:10.1186/1472-698X-9-6

[6] Kim, T.H., Chun, K.H. and Kim, H.J. (2012) Direct medical costs for patients with type 2 diabetes and related complications: A prospective cohort study based on the Korean national diabetes program. Journal of Korean Medical Sciences, 27, 876-882. doi:10.3346/jkms.2012.27.8.876

[7] American Diabetic Association (2008) Economic costs of diabetes in the US in 2007. Diabetes Care, 31, 596-615.

[8] Canadian Diabetes Association (2010) An economic tsunami: The cost of diabetes in Canada.

[9] Diabetes UK (2010) Diabetes in the UK 2010: Key statistics on diabetes.

http://www.diabetes.org.uk/Documents/Reports/Diabetes in_the_UK_2010.pdf

[10] International Diabetes Federation (2011) IDF Diabetes Atlas. 5th Edition, IDF, Bressels.

[11] World Health Organisation (2013) Morocco health profile. http://www.who.int/gho/countries/mar.pdf

[12] Moroccan Ministry of Health (2010) Santé vision 2020. http://www.sante.gov.ma/Vision/Sante-Vision\%202020.p df

[13] Tazi, M.A., Abir-Khalil, S., Chaouki, N., Cherqaoui, S., Lahmouz, F. and Srairi, J.E. (2000) Prevalence of the main cardiovascular risk factors in Morocco: Results of a National Survey 2000. Journal of Hypertension, 21, 897903. doi:10.1097/00004872-200305000-00013

[14] Ramdani, N., Vanderpas, J., Boutayeb, A., Meziane, A., Hassani, B., Zoheir, J., Legssyer, A., Aziz, M., Mekhfi, H., Bnouham, M. and Ziyyat, A. (2012) Diabetes and obesity in the eastern Morocco. Mediterranean Journal of Nutrition and Metabolism, 5, 149-155. doi:10.1007/s12349-011-0087-2

[15] Boutayeb, A., Lamlili, M., Boutayeb, W., Maamri, A., Ziyyat, A. and Ramdani, N. (2012) The rise of diabetes prevalence in the Arab region. Open Journal of Epidemiology, 2, 55-60.

[16] National Agency of Health Insurance (2013) Agence nationale assurance maladie: ANAM.

http://www.assurancemaladie.ma/anam.php?id_espace=6 
[17] Bjork, S. (2001) The cost of diabetes and diabetes care. Diabetes Research and Clinical Practice, 54, S13-S18. doi:10.1016/S0168-8227(01)00304-7

[18] Murray, C. and Lopez, A.D. (1996) Global health statistics: A compendium of incidence, prevalence and mortality estimates for over 200 conditions. World Health Organization, Geneva.

[19] Khowaja, L.A., Khuwaja, A.K. and Cosgrove, P. (2007) Cost of diabetes care in out-patient clinics of Karachi, Pakistan. BMC Health Services Research, 7, 189. doi:10.1186/1472-6963-7-189

[20] Boutayeb, A. (2012) Reader's comments: Discussion of estimation parameters. BMC International Health and Human Rights, 9, 6. http://www.biomedcentral.com/1472-698X/9/6/comment $\underline{\mathrm{s}}$

[21] Boutayeb, A. (2006) The double burden of communicable and non-communicable diseases in developing countries. Transactions of the Royal Society of Tropical Medicine and Hygiene, 100, 191-199.

doi:10.1016/j.trstmh.2005.07.021

[22] UKPDS (UK Prospective Diabetes Study) Group (1998) Intensive blood-glucose control with sulphonylureas or insulin compared with conventional treatment and risk of complications in patients with type 2 diabetes (UKPDS 33). Lancet, 352, 837-853. doi:10.1016/S0140-6736(98)07019-6

[23] Venkat, K.M., Zhang, N.P., Kanaya, A.M., Williams, D.E., Engelgau, M.M., Imperatore, G. and Ramachandran, A. (2006) Diabetes: The pandemic and potential solutions. In: Jamison, D.T., et al., Eds., Disease Control Priorities in Developing Countries, World Bank, Washington DC, 2006. 